\title{
Çalışanların Farklılıkların Yönetimi İle İlgili Algılarının İş Tatminine Etkisini Belirlemeye Yönelik Bir Araştırma ${ }^{1}$
}

\author{
DOI: $10.26466 /$ opus.639658
}

\author{
Mehmet Emre Güler - Tuğba Saraç \\ * Prof. Dr., İzmir Kâtip Çelebi Üniversitesi, Turizm Fakültesi, Çiğli / İzmir/ Türkiye \\ E-Posta: memre.guler@ikc.edu.tr \\ ORCID: $\underline{0000-0002-8689-9859}$ \\ ** Yönetici Yrd., Caresse a Luxury Collection Resort, Misafir İlişkileri Böl, Bodrum/Muğla/Türkiye \\ E-Posta: tugbasarac88@gmail.com \\ ORCID: $\underline{0000-0003-4786-3754}$ \\ *** Yönetici, The Ritz-Carlton Hotel, Odalar Bölümü, Cidde / Suudi Arabistan \\ E-Posta: osmanalmadag@gmail.com \\ ORCID: $\underline{0000-0003-3184-2828}$
}

Öz

Farklılıkların Yönetiminin büyük önem arz ettiği bu zamanlarda özellikle çokuluslu işletmelerin iç çatışmaları engelleyerek işletmeyi daha da ileriye taşımak ve geliştirmek için belli politikalar oluşturması ve eğitimler düzenlemesi gerekmektedir. Bu durum bireysel olarak gelişimi sağlayabileceği gibi örgütsel olarak da çalışma barışı ve işyeri atmosferinin gelişimi açısından bir firsat ortaya koyacaktır. Öte yandan çalışanların iş tatmininin hizmet işletmelerinin başarısında önemli bir rol oynamakta ve bu rol müşterinin tatminine de sağlayabilen ve bununla birlikte müşteri bağhllı̆̆ın arttıran bir faktör olabilmektedir. Bu bağlamda, iş tatmininin să̆lanması ile ilgili çalışmalar, özellikle çok uluslu zincir işletmelerde farklılıkların yönetimi uygulamaların daha önemli hale getirmektedir. Çalışmada Uluslararası bir otel zincirinin farklılıkların yönetimi ile ilgili faaliyetlerinin çalışanlar tarafindan nasıl algılandığına ve bunun çalışanların iş tatminine etkilerinin belirlenmesine yönelik bir araştırma yapılmıştır. Çalışmanın bulgularına göre söz konusu zincir otel işletmesi farklılıkların yönetimi hakkında eğitimler düzenlemekte, çalışanlarını farklılıklar konusunda bilinçlendirmekte, bu durum ise çalışanlar tarafından olumlu şekilde algılanmakta ve iş tatminine de olumlu biçimde yansimaktadır.

Anahtar Kelimeler: Farklılık, Farklılıkların Yönetimi, İ̧̧ Tatmini, Zincir Otel

\footnotetext{
${ }^{1}$ Bu çalışma İzmir Kâtip Çelebi Üniversitesi, Sosyal Bilimler Enstitüsü, Turizm Iş̧letmeciliği Anabilim Dalı bünyesinde hazırlanan Tezsiz Yüksek Lisans Projesinden türetilmiştir
} 


\title{
Research on Determining the Impact of Employees' Perception of Diversity Management on Job Satisfaction
}

\begin{abstract}
In today's world, where Diversity Management is of great importance, multinational enterprises should form specific policies and organize training in order to prevent and further develop internal conflicts. This situation can provide individual development as well as an organizational opportunity for work peace and the development of the workplace atmosphere. On the other hand, job satisfaction of the employees plays an essential role in the success of service companies, and this role can also be a factor that can provide customer satisfaction and increase customer loyalty. In this context, work on ensuring job satisfaction makes management of differences more critical, especially in multinational chain enterprises. In this study, research has been conducted to determine how the activities of an international hotel chain related to the management of differences are perceived by the employees and its effects on the job satisfaction of the employees. According to the findings of the study, the said chain hotel company organizes training on the management of the differences, raises the employees' awareness about the differences, and this situation is perceived positively by the employees and has a positive effect on job satisfaction.
\end{abstract}

Keywords: Diversity, Diversity Management, Job Satisfaction, Hotel Chain 


\section{Giriş}

Dünya çapındaki demografik, ekonomik, politik, teknolojik değişim ve gelişimlere bağlı olarak birçok şirket ulusal sınırlarının dışına çıkıp genişlemiştir (Gröschl, 2011, Brodbeck vd., 2000). Günümüzde Çok Uluslu İşletmelerin artmasıyla birlikte işletmelerin örgütsel yapılarında da değişiklikler ortaya çıkmıştır. Bu farklılığın istihdama olumlu etkisini ve uyumunu sağlama yolunda işletmeler, çalışanların demografik, etnik ve kültürel farklılığından etkili bir şekilde faydalanabilmeli, bunun için de farklılıklara uygun politikalar geliştirmelidir (Manoharan vd., 2014). Dolayısıyla, işletmelerin menfaatine olan bu çeşitliliğin var olan düzenle uyumlu devam etmesinin sağlanmasında Farklılıkların Yönetimi büyük önem kazanmıştır.

İş gücü farklılı̆̆ının anlamı yıllar geçtikçe değişmiştir. Bu bağlamda önceleri cinsiyet veya etnik köken ile sınırlı tutulan kavramın kapsamı, yaş, eğitim durumu, cinsel yönelim, fiziksel kabiliyet, sosyal statü, ekonomik durum, yaşam tarzı, din değişkenleri ile genişletilmiştir. Özetle farklılık, çok boyutlu bir kavramdır ve yönetimi kritik bir önem taşımaktadır. Bu çalışma uluslararası bir otel zincirinin farklı coğrafyalardaki iki otelinde bulunan çalışanları kapsamaktadır. Bu kapsamda farklılıkların yönetimi uygulamalarının çalışan devir hızı yüksek olan otel işletmelerinde iş tatminine olan etkisine araştırılarak literatüre katkı sağlanmaya çalışılacaktır. Yapılan incelemelerde çalışanların farklılıkların yönetimi uygulamalarına yönelik algılarının iş tatminine etkisini inceleyen çalışmalara konaklama işletmeleri özelinde literatürde çok fazla üzerinde durulmadığı görülmüştür.

\section{Kavramsal Çerçeve}

Çalışmanın bu kısmında farklılıkların yönetimi ve iş tatmini kavramlarına yer verilmektedir. Sonrasında Konaklama sektöründe farklılıkların yönetimi ile ilgili yapılan çalışmalarla iş tatminine etkisine yönelik çalışmalar ele alınmıştır.

\section{Farklılıkların Yönetimi Kavramı}

"Farklı olma durumu, ayrımlılık, başkalık" şeklinde tanımlanan farklılık kavramı felsefi anlamda, “Doğal, toplumsal ve bilince dayanan her olay ve 
olguyu bütün ötekilerden ayıran özellik" olarak ifade edilmektedir (TDK, 2017). Farklılık ayrıca, "grup üyeleri arasında nesnel veya öznel farklılıkların ne dereceye kadar var olduğunu yansitan sosyal gruplamanın bir özelliği" olarak da tanımlanmaktadır (Van Knippenberg ve Schippers, 2007, 516). Farklılık kavramı ırk ve etnik köken (McKay vd., 2008), kültür (Akyol, 2016), cinsiyet (Pearsall vd., 2008, Peccei ve Lee, 2005), engellilik (McLaughlin vd., 2004), davranış biçimleri (Nişancı vd., 2016) ve yaş farklılıklarını kapsamaktadır (Kunze vd., 2011).

Farklılıkların yönetimi düşüncesi Amerika Birleşik Devletleri'nde ortaya çıkmış, akademik katkıların farklı insanları hem tanıma hem de yönetme konusundaki örgütsel ve bireysel menfaate odaklandığı görülmüştür. Buna göre çalışanlar arasında farklılıklar vardır ve bunların anlaşılıp düzgün yönetilmesiyle daha verimli ve etkili bir çalışma ortamı sağlanabilir (Bartz vd., 1990).

Farklılıkların yönetimi, ticaretin uluslararasılaşmasından, dünya pazarlarının gelişmesinden, artan işgücü hareketliliğinden ve bireysel farklılıklara yönelik artan farkındalıktan kaynaklanan avantajlardan yararlanmaktadır (Lawler, 1996; Sürgevil ve Budak, 2008). Ayrıca eşit istihdam firsatı, dışarıdan başlayıp mevzuat yoluyla uygulanırken, farklılık yönetimi, eşitlik atmosferine dayanan ve kapsayıcı bir örgüt kültürü yaratılması ile başlamaktadır (Gordon, 1995; Sürgevil, 2008). Diğer bir deyişle bu tartışmalar, eşit istihdam firsatı ve pozitif ayrımcılık taahhüdünü içeriyor olsa da, farklılıkların yönetimi gerçekte daha geniş kapsamlıdır (Kossek vd., 2005). Bu doğrultuda farklılıkların yönetimi ilk olarak, ırk, cinsiyet ve sınıf gibi bireysel farklılıklara dayalı eşitsizliklere değinerek işgücü piyasasındaki ayrımcılığın üstesinden gelmeyi hedeflemekte; ikincisi ise, herkesin kendi potansiyelini en üst düzeye çkarabilmesi için hukuka uygun eşit istihdam fırsatının ötesinde bireysel farklılıklara değer vermeyi ve bunlardan yararlanmayı vurgulamaktadır (Horwitz vd., 1996).

Farklılıkları yönetmek, yöneticilerin bilinçlendirilmesine ve dikkatlerinin çekilmesine ilişkin çeşitli etkinlikleri kapsamaktadır. Bu etkinlikler; farklı grupların üyelerinin çalışma hayatı içerisindeki işbirliği, rekabet etme, iletişim kurma, planlama, organize etme ve motive etme biçimlerini etkileyebilecek değer ve varsayımları desteklemektedir (Langer, 1989). Böylece, farkl1lıkları değerlendirebilme amacına uygun olarak, her bireyin veya alt grubun güçlü yönlerinin kullanılması ile sinerji yaratılabilmektedir (Tung, 1995). 
Etkili farklılık yönetimi sayesinde, farklı ekipler daha fazla yenilik ve yaratıcllık elde etmeyi hedeflemekte ve böylece homojen ekiplere göre üstünlük sağlamaktadır (Cox ve Blake, 1991; Richard, 2000; Eroğlu ve Çalışır, 2019). Başka bir ifadeyle, problem çözme konusunu daha geniş bir yelpazede ele alan farklı ekipler, hız ve yeniliği teşvik edebilmekte ve önemli ölçüde daha kaliteli çözümler üretebilmektedir.

Farklılık nedeniyle ortaya çıkan sorunların göz ardı edilmesi, çalışanlar arasında potansiyellerini olumsuz etkileyen çatışmalara yol açarken (Christensen-Hughes, 1992; Sürgevil, 2008); iyi yönetilen farklılıklar, işin devamlllığını ve esnekliğini sağlayan farklı bakış açıları ve deneyimler sunarak fırsatlar ve faydalar ortaya çlkarabilmektedir (Day, 2007; Budak vd., 2009).

İşe alım sürecinde hariç tutulan azınlıkların daha iyi temsil edilmesini amaçlayan ve gelişmiş bir strateji serisi olarak ifade edilen farklılıkların yönetimi (Wrench, 2008), insan kaynakları yönetimi uygulamalarından yararlanarak (i) insan sermayesi çeşitliliğini arttırmak ve sürdürmek ve/veya (ii) belirli düzeyde insan sermayesi çeşitliliğinin örgütsel amaçların başarılmasını engellemesini önlemek ve/veya (iii) belirli düzeydeki insan sermayesindeki değişimle örgütsel hedeflerin başarılmasını sağlamak (Olsen ve Martins, 2012: 1161) şeklinde de tanımlanabilmektedir.

Farklılıkların Yönetiminin örgütsel faydaları aşağıdaki gibi sıralanabilmektedir (Cox ve Blake, 1991):

1. Maliyeti ve devamsızlığı azaltma,

2. En iyi personeli çekme,

3. Pazarlama çabasına kültürel duyarlılık getirme,

4. Yaratıcılığ 1 ve yeniliği arttırma,

5. Problem çözme hususunda daha kapsamlı kritik analiz yapabilme,

6. Çevreye daha hizlı ve daha az maliyetle tepki verme.

Bunun yanı sıra farklılıkları etkili yöneten örgütlerde maliyet, kaynak toplama, pazarlama, yaratıcılık, problem çözme ve örgütsel esneklik alanlarında rekabet avantajı yaratılabileceği savunulmakta ve daha fazla organizasyonel üretkenlik ile daha yüksek kâr elde edilebileceği ileri sürülmektedir (Cox ve Blake, 1991). 


\section{İş Tatmini Kavramı}

Pek çok araştırmacı tarafından farklı şekillerde tanımlanan iş tatmini öncelikle, "kişilerin mesleklerinden ne kadar memnun oldukları, işlerini sevip sevmedikleri veya yaptıkları iş ile bireysel özelliklerinin uyumu ile ilgili sonuç" olarak ifade edilebilmektedir. Çalışanlar tatmin olduklarında; gözlemleri, duygusal deneyimleri, inançları ve duyguları bakımından işlerini olumlu bir şekilde değerlendirmektedirler. Dolayısıyla, birey için neyin önemli olduğundan ziyade onun neyi arzu ettiği ön plandadır. En yaygın tanımlardan biri ise, "kişinin iş veya iş deneyimlerinin değerlendirilmesinden kaynaklanan zevkli ya da olumlu bir duygusal durum" şeklindedir (Locke, 1976, s.1304).

İş tatmini, çalışanların işin gerçek koşullarına yönelik duygusal tepkileri olmasının yanı sıra, onların motivasyonları ve ihtiyaçlarının giderilmesi için itici güç olarak ortaya çıkmaktadır. Diğer bir deyişle iş tatmini, çalışan ve işverenin karşılıklı beklentilerinin uyumundan etkilenmekte; kişisel ve organizasyonel faktörlerin bir arada değerlendirilmesi ile tatmin ya da tatminsizlik oluşmaktadır. Bu faktörlerden bazıları; iş yaşam kalitesi, çalışma koşulları, çalışma ortamı, farklılıklarla ilgili çalışmalar, çalışanların psikolojik, ekonomik ve sosyal ihtiyaçlarının karşılanması şeklinde sıralanabilmektedir (Parvin ve Kabir, 2011). İş tatmini veya tatminsizliği ayrıca; yaş, cinsiyet, eğitim düzeyi gibi demografik unsurlardan da etkilenmektedir (Sinha ve Shukla, 2013). Pitts (2009) çalı̧̧masında, beyaz olmayan çalışanların, beyaz çalışanlardan daha yüksek düzeyde iş tatmini olasılı̆̆ı daha düşüktür, ayr1ca, erkeklerin kadınlardan daha yüksek iş doyumu gösterme olasılıkları daha düşüktür, daha yüksek yönetim otoritesine sahip olanların yüksek iş memnuniyetini rapor etme olasılıkları daha yüksektir sonucunu rapor etmektedir. Ordu (2016) ise çalışmasında farklılıkların yönetimi uygulamaları ile iş tatmini arasında ve farklılıkların yönetimi ile bireysel performans arasinda anlamlı pozitif ilişki bulunduğunu belirtmiştir.

Sonuç olarak iş tatmini, çalışana ödenen ücret ile doğrudan bağlantılı olmayıp; adil davranışa dair bir algıdır. Bu bağlamda, farklılıkların yönetimi uygulamalarının iş tatmininin belirleyicilerinden olduğu söylenebilmektedir (Witt ve Nye, 1992, s.910). 


\section{Konaklama Sektöründe Farklılıklarn Yönetimi ve İş Tatmini}

Uluslararasılaşma, dramatik demografik gelişmeler ve hizmet sunumunun kültürel olarak göreli ve tanımlanmamış bir sosyal deneyim oluşu, çokuluslu birçok konaklama işletmesinin insan kaynağına dair kültürel farklılık sorunlarını yönetmesini gerekli kılmıştır (Christensen-Hughes, 1992; Barrows ve Powers, 2008). Bu doğrultuda, çalışanların becerilerini ve potansiyellerini kullanarak, değişen bir pazara erişim ve insan sermayesinden sağlıklı bir geri dönüş sağlanabilmektedir (Gardenswartz ve Rowe, 1998). Ayrıca, işyeri çekiciliğinin arttırılması ile (Nykiel, 1997) en iyi yetenekler elde edilip, sürdürülebilir hale getirilebilmektedir (Ross ve Schneider, 1992; Iles, 1995). Farklılıkların yönetimi yaklaşımının bir diğer faydası ise, satış ve devamsızlık ile bağlantılı maliyetlerin düşürülmesi (Ross ve Schneider, 1992; Kandola, 1995) ve örgüt içinde daha fazla yaratıcılığın söz konusu olmasıdır (McNerney, 1994; Iles, 1995; Gardenswartz ve Rowe, 1998). Özetle, yüksek personel devri ve iş başarısızlığı, farklılıkların yönetimi yoluyla hafifletilebilmektedir (Groschl ve Doherty, 1999). Bununla birlikte, konaklama sektöründe farklılıkların yönetimi üzerine yapılmış sınırlı sayıda araştırmada, otel işletmelerinin bu konunun faydalarını henüz yeterince özümseyememiş oldukları ileri sürülmektedir (Cox ve Blake, 1991; Groschl ve Doherty, 1999: 266). Öte yandan İngiltere'de ise, konaklama sektöründe farklılıkların yönetiminin daha fazla işverenin ilgisini çektiği belirtilmektedir (Iles, 1995). Madera vd. (2013) yaptıkları çalışmada; farklılıklara yönelik olumlu bir iklimin söz konusu olduğu otel işletmelerinde, rol belirsizliği ve rol çatışmasının azaldığını, iş tatmininin ise arttığını ifade etmektedirler. Madera vd. (2016), otel yöneticilerinin psikolojik farklılık ortamlarının iş tatminlerini, ırk-etnik azınlık statüsünün moderatif etkisi ve örgütsel adaletin aracı rolü ile nasıl etkilediğini inceleyen bir model geliştirmişler ve yöneticilerin psikolojik farklılık ortamlan ile iş tatmini arasındaki ilişkide moderatif ve aracılık ilişkilerini destekleyici sonuçlar elde etmişlerdir.

\section{Yöntem}

Dünya çapındaki demografik, ekonomik, politik, teknolojik değişim ve gelişimlere bağlı olarak birçok şirket ulusal sınırlarının dışına çıkıp genişlemiştir (Gröschl ve Doherty, 1999, Brodbeck vd., 2000). Bu bağlamda, söz konu- 
su değişim ve gelişmelerin istihdam sonuçlarına uyumunu sağlamak için uluslararası nitelikteki oteller de, çalışanların demografik, etnik ve kültürel farklılığından etkili bir şekilde faydalanmaya yönelik uygulamalar gerçekleştirmeye ihtiyaç duymaktadırlar (Manoharan vd., 2014). Söz konusu araştırmada, uluslararası düzeyde faaliyet gösteren bir otel zincirinde farklılıkların yönetimi ile ilgili uygulamaların çalışanlar tarafından nasıl algıladığını ortaya koyup, bu algının iş tatminine etkisini saptamak amaçlanmaktadır.

Veriler, araştırma konusu otel zincirinin İstanbul ve Cidde'deki işletmelerinin tüm departmanlarında çalışanlarından, 1 ay içerisinde çevrimiçi olarak elde edilmiştir. İki otelde tam ve kısmî zamanlı olarak yaklaşık 450 çalışan olduğu bildirilmiştir. Kolayda örneklem metodu ile araştırmaya dâhil olan 149 katılımcıya çalışmanın amacı hakkında gerekli ön bilgiler verilmiştir.

Öncelikle demografik bilgiler incelenmiş, çalışanlara ilişkin milliyet, yaş, istihdam şekli, cinsiyet, medeni durum, eğitim ve çalışma tecrübesi verilerine ulaşılmıştır. Bunun yanı sıra farklılıkların yönetimi ile ilgili uygulamalara dair algıları ve iş tatmini durumunu ölçmeye yönelik sorular Davis (2008)'in çalışmasından elde edilmiş ve bu çalışmaya göre uyarlanarak oluşturulmuştur.

\section{Bulgular}

Öncellikle veriler, SPSS istatistik yazılımı üzerinde düzenlenmiş ve analize uygun hale getirilmiştir. Elde edilen bulgular sırasıyla; demografik değişkenler, farklılıkların yönetimi uygulamaları, iş tatmini ve farklılıkların yönetimi uygulamalarının iş tatmini üzerindeki etkisi ile ilgili olmakla birlikte analizler SPSS ve AMOS yazılımları ile gerçekleştirilmiştir.

\section{Katılımcılara İlişkin Demografik Bulgular}

Katılımcıların demografik verilerine ilişkin elde edilen bulgular aşağıdaki tabloda özetlenmektedir. 
Tablo 1. Katılımciların Demografik Profili

\begin{tabular}{|c|c|c|c|}
\hline ÖZELLİKLER & & Kişi Sayısı & $\%$ \\
\hline \multirow{2}{*}{ Cinsiyet } & Kadın & 16 & 10,7 \\
\hline & Erkek & 133 & 89,3 \\
\hline \multirow{5}{*}{ Yaş } & 18-25 yaş & 24 & 16,1 \\
\hline & $26-33$ yaş & 55 & 36,9 \\
\hline & $34-41$ yaş & 53 & 35,6 \\
\hline & $42-48$ yaş & 15 & 10,1 \\
\hline & 49-56 yaş & 2 & 1,3 \\
\hline \multirow{2}{*}{ Medeni Durum } & Evli & 101 & 67,8 \\
\hline & Bekâr & 48 & 32,2 \\
\hline \multirow{5}{*}{ Eğitim Düzeyi } & İlköğretim & 4 & 2,7 \\
\hline & Lise & 33 & 22,1 \\
\hline & Lisans & 103 & 69,1 \\
\hline & Yüksek Lisans & 8 & 5,4 \\
\hline & Doktora & 1 & 0,7 \\
\hline \multirow{6}{*}{ Milliyet } & Asyalı & 58 & 38,9 \\
\hline & Hint & 50 & 33,6 \\
\hline & Türk & 36 & 24,2 \\
\hline & İranlı & 11 & 0,7 \\
\hline & Afrikalı & 2 & 1,3 \\
\hline & Avrupalı & 2 & 1,3 \\
\hline \multirow{6}{*}{ Sektör Tecrübesi } & 1 yıla kadar & 5 & 3,4 \\
\hline & $1-5$ yıl & 38 & 25,5 \\
\hline & 6-10 yıl & 52 & 34,9 \\
\hline & $11-15 \mathrm{yll}$ & 33 & 22,1 \\
\hline & $16-20$ yıl & 14 & 9,4 \\
\hline & 21 yıl ve üzeri & 7 & 4,7 \\
\hline \multirow{2}{*}{ İstihdam Şekli } & Tam zamanlı & 148 & 99,3 \\
\hline & Kısmî zamanlı & 1 & 0,7 \\
\hline
\end{tabular}

Toplanan verilere göre katılımcların \%10,7'si kadın, 89,3'ü erkektir. Buna göre otel çalışanlarının büyük bir kısmının erkek olduğu gözlenmektedir. Katılımcların \%36,9'luk yüzde ile çoğunluğunu 26-33 yaş aralığındaki bireyler oluşturmaktadır. Bu grubu \%35,6'lık bir yüzde ile 34-41 yaş grubu takip etmektedir. 18-25 yaş aralığındaki çalışanlar ise \%16,1'lik dilimde yer almaktadır. 42-48 yaş grubundaki katılımclar, 49-56 yaş grubundakilerden daha fazladır. Azınlık grubu, \%1,3'lük yüzde ile 49-56 yaş aralığındaki çalışanlar oluşturmaktadır. Verilere göre evli olanlar $(\% 67,8)$, bekâr olanlardan $(\% 32,2)$ daha fazladır. Ayrıca katılımcların \%69,1'i lisans, \%22,1'i lise, $\% 5,4$ 'ü yüksek lisans, \%2,7'si ilköğretim, \%0,7'si ise Doktora mezunudur. Dolayısıyla lisans mezunlarının sayısının çoğunlukta olduğu görülmektedir. Bunların yanı sira katılımcların \%38,9'u Asyalı, \%33,6's1 Hint, \%24,2'si Türk, \%1,3'ü Afrikalı, \%1,3'ü Avrupalı ve \%0,7'si İranlı'dır. Katılımcıların 
\%4,7'si 21 yıl ve daha fazla, \%9,4'ü 16-20 yıl arası, \%22,1'i 11-15 yıl arası, \%34,9'u 6-10 yıl arası, \%25,5'i 1-5 yıl arası ve \%3,4'ü 1 yıla kadar iş tecrübesi olan katılımcların; \%99,3'ü tam zamanlı ve \%0,7'si ise kısmi zamanlı çalışmaktadır.

\section{Farklılıkların Yönetimine İlişkin Tanımlayıcı İstatistikler}

Katılımcların farklılıkların yönetimi ile ilgili yapılan uygulamalara ilişkin görüşleri aşağıdaki tabloda özetlenmektedir.

Tablo 2. Farklılıkların Yönetimi İfadelerine İlişkin Tanımlayıcı İstatistikler

\begin{tabular}{|c|c|c|c|}
\hline & $\mathbf{N}$ & Ort. & S.S. \\
\hline F1. İsyerimde farklılıklarla ilgili iyi bir uyum programı bulunmaktadır. & 149 & 4,56 & ,682 \\
\hline $\begin{array}{l}\text { F2. İşyerimde farklılıklar ve kültürel yetkinlikler konusunda aktif hizmet içi programlar } \\
\text { bulunmaktadır. }\end{array}$ & ${ }_{149}$ & 4,54 & ,712 \\
\hline F3. Farklılıklarla ilgili kararlar alınırken çalışma arkadaşlarıma destek veriyorum. & 149 & 4,59 & ,647 \\
\hline F4. Yöneticiler, işyerindeki farklılıklar konusunda diğer çalışanları desteklemektedir. & 149 & 4,52 & ,722 \\
\hline F5. İşyerimde çalışanlarla ilgili olarak farklılıklar tanımlanmıştır. & 149 & 4,56 & 651 \\
\hline F6. İsyerimde farklılıklarla ilgili olarak oluşturulan politikalar bulunmaktadır. & 149 & 4,48 & ,768 \\
\hline F7. Farklılıklarla ilgili eğitimler zaman kaybıdır. & 149 & 1,87 & ,995 \\
\hline F8. Verilen farklılık eğitimi, gey işçilerle olan etkileşimleri içermektedir. & 149 & 4,15 & 971 \\
\hline F9. Yöneticiler farklılık konusunu ciddi olarak ele almaktadır. & 149 & 4,50 & 674 \\
\hline F10. Toplum, benim bulunduğum ortamdaki farklılıkların farkındadır. & 149 & 4,46 & ,749 \\
\hline $\begin{array}{l}\text { F11. Toplumsal cinsiyetle ilgili farklılık konuları benim bulunduğum ortamın odak noktas } \\
\text { olmustur. }\end{array}$ & 149 & 4,36 & ,847 \\
\hline F12. Bulunduğum ortamda, başkalarıyla kültürel yetkinliği tartışabilirim. & 149 & 4,30 &, 898 \\
\hline
\end{tabular}

Tablo incelendiğinde, katılımcların otel zincir yönetimi tarafından gerçekleştirilen farklılıkların yönetimi uygulamalarına bakış açılarının ve algilarının olumlu yönde olduğu anlaşılmaktadır. Düşük ortalama ile ifade edilen tek madde, farklılıkların yönetimi ile ilgili yapılan eğitimlerin zaman kaybı olarak değerlendirilmesidir ki bu durum da tutarlılık göstermektedir.

Tablo 3. Farklılıklarn Yönetimine İlişkin Faktör Analizi Sonuçları

\begin{tabular}{ll}
\hline İfadeler & Faktör Yükleri \\
\hline F4 &, 955 \\
F5 & 950 \\
F2 & 942 \\
F1 & 932 \\
F3 & 938 \\
\hline
\end{tabular}




\begin{tabular}{ll}
\hline F10 &, 926 \\
F9 &, 925 \\
F6 &, 911 \\
F11 &, 709 \\
F12 &, 703 \\
F8 &, 637 \\
\hline Aç1klanan Varyans (\%) & 76,308 \\
Cronbach $\alpha$ & 0,932 \\
\hline
\end{tabular}

Farklılıkların Yönetimi ile ilgili sorulara yapılan açıklayıcı faktör analizine göre tüm ifadeler $\% 76,308$ 'lik varyans açıklama değeri ile tek faktör altında toplanmış ve ayrıca ölçeğin güvenilirlik değeri 0,932 olarak bulunmuştur.

\section{İş Tatminine İlişkin Bulgular}

Katılımcların çalıştıkları zincir otelinde hissettikleri iş tatmini ile ilgili bulgular aşağıdaki tabloda özetlenmektedir.

Tablo incelendiğinde, katılımcların iş tatmin düzeylerinin yüksek olduğu anlaşılmaktadır. Orta derece ile ifade edilen tek yön, katılımcıların boş zamanlarından iş yaşamında olduğundan daha çok keyif almalarına ilişkindir.

\section{Tablo 4. İş Tatmini İfadelerine İlişkin Tanımlayıcı İstatistikler}

\begin{tabular}{lccc}
\hline & N & Ort & S.S. \\
\hline T1. Genel olarak, işimden oldukça memnun olduğumu söyleyebilirim. & 149 & 4,58 &, 669 \\
T2. Liderim işine çok bağlıdır. & 149 & 4,55 &, 641 \\
T3. İş arkadaşlarımla kişiler arası iyi ilişkilerim var. & 149 & 4,57 &, 670 \\
T4. Liderim işini biliyor. & 149 & 4,58 &, 659 \\
T5. Boş zamanlarım işimden daha çok zevklidir. & 149 & 3,03 & 1,400 \\
T6. İşlerim konusunda çoğu zaman hevesliyim. & 149 & 4,45 &, 702 \\
T7. Genel olarak, şu anki işimden oldukça memnun olduğumu söyleyebilirim. & 149 & 4,52 &, 684 \\
T8. İşim her zaman elimden gelenin en iyisini yapmam için beni zorluyor. & 149 & 4,53 &, 693 \\
T9. Ben iyi bir yönetici ve liderim. & 149 & 4,49 &, 703 \\
T10. Keyifli bir iş ortamını tercih ediyorum. & 149 & 4,56 &, 630 \\
\hline
\end{tabular}

Tablo incelendiğinde, katılımcların iş tatmin düzeylerinin yüksek olduğu anlaşılmaktadır. Orta derece ile ifade edilen tek yön, katılımcıların boş zamanlarından iş yaşamında olduğundan daha çok keyif almalarına ilişkindir. 
Tablo 5. İş Tatminine İlişkin Faktör Analizi Sonuçları

\begin{tabular}{ll}
\hline İfadeler & Faktör Yükleri \\
\hline T7 &, 973 \\
T6 &, 965 \\
T9 &, 964 \\
T3 &, 953 \\
T10 &, 950 \\
T1 &, 949 \\
T2 &, 942 \\
T8 &, 930 \\
T5 &, 894 \\
T4 &, 709 \\
\hline Açklanan Varyans (\%) & 89,654 \\
\hline Cronbach $\alpha$ & 0,931 \\
\hline
\end{tabular}

İş tatmini ile ilgili sorulara yapılan açıklayıc faktör analizine göre tüm ifadeler \%89,654'lük varyans açıklama değeri ile tek faktör altında toplanmış ve ayrıca ölçeğin güvenilirlik değeri 0,931 olarak bulunmuştur.

\section{Farklılıkların Yönetimi Uygulamalarının İş Tatminine Etkisi}

Çalışanların farklılıkların yönetimi uygulamalarına dair algıları ile iş tatminleri arasındaki ilişkiyi belirlemeye yönelik korelasyon analizi sonuçlarına göre, iki değişken arasında 0,01 önem seviyesinde pozitif güçlü $(0,714)$ bir ilişki olduğu saptanmıştır. Bağımsız değişken olarak farklılıkların yönetimi ile ilgili algıların, bağımlı değişken olan iş tatminini açıklama katsayısı $(0,51)$ ise yeterli bir seviye olarak değerlendirilebilir. Farklılıkların Yönetimi uygulamalarına ilişkin algıların iş tatminine etkisine yönelik yapılan regresyon analizi sonuçları ise aşağıdaki tabloda özetlenmektedir.

Tablo 6. Regresyon Analizine İlişkin Bulgular

\begin{tabular}{lllllll}
\hline & & & Tahmin & S.E. & C.R. & P \\
\hline Farklılıkların Yönetimi & $\rightarrow$ & İş Tatmini &, 735 &, 059 & 12,417 & ${ }^{* * *}$ \\
\hline
\end{tabular}

Tablo 6'da verilen bulgulara göre, farklılıkların yönetimi ile ilgili algılardaki bir birimlik artış iş tatmininde 0,735 birimlik bir artış sağlayacaktır. $\mathrm{Bu}$ doğrultuda, farklılıkların yönetimi ile ilgili uygulamalara yönelik algıların iş tatminini yüksek derecede ve olumlu yönde etkilediği söylenebilir. 


\section{Tartışma ve Sonuç}

Çokuluslu işletmelerin farklılıkların yönetimi ile ilgili belli politikalar izlemesi ve kaynaştırma programları uygulaması, örgüt içindeki işleyiş açısından büyük önem arz etmektedir. Araştırmaya katılan bireylerin 6 değişik milliyetten olması, çalışmaya konu olan işletmenin bu bağlamda değerlendirilmesini geçerli kılabilmektedir. "İş yerimde farklılıklarla ilgili iyi bir uyum programı bulunmaktadır" ve "Isşyerimde farklılıklar ve kültürel yetkinlikler konusunda aktif hizmet içi programlar bulunmaktadır" sorularını olumlu cevaplayanların oranı, araştırmanın yapıldığı zincir otelin, farklılıkların yönetimi konusunda bir uyum programına sahip olduğunu göstermektedir. Ayrıca çalışanların farklılıklara yönelik bilinç düzeyleri de, "Farklılıklarla ilgili kararlar alınırken çalışma arkadaşlarıma destek veriyorum" ve "Yöneticiler, işyerindeki farklılıklar konusunda diğer çalışanları desteklemektedir" sorularına verilen yüksek orandaki olumlu cevapla ortaya konmaktadır. Ayrıca, aktif hizmet içi eğitim programlarının kurum içi bilinçlendirmeyi kapsadığı da olumlu cevap oranlarından anlaşılmakta, farklılıkların yönetimi eğitimlerinin içeriğinde azınlıklara dair politikalar olduğu ise, "Verilen farklılık eğitimi, gey işçilerle olan etkileşimleri içermektedir" sorusuna verilen olumlu yanitlarla desteklenmektedir.

Çalışmanın amacı doğrultusunda, katılımcılar tarafından olumlu bir şekilde algılanan farklılıkların yönetimi uygulamalarının iş tatminine etkisinin de pozitif yönde olduğu saptanmıştır. Bu bağlamda, işletmeler tarafından gerçekleştirilen bu tür uygulamalar ile çalışanların bir birey olarak görüldüğü ve farklılıklarına değil yetkinliklerine göre değerlendirildikleri algılanabilmekte ve bu durum iş tatminini arttırıcı bir etki sağlayabilmektedir. Bu bağlamda Madere vd. (2013) ve Madera vd. (2016)'nın çalışmalarında olduğu gibi farklılıkların yönetimi uygulamalarının iş tatmini üzerinde olumlu bir etkiye sahip olduğu sonucu, otel işletmeleri özelinde, bu çalışma ile de zincir otellerinde yapılan araştırmayla desteklenmektedir.

İlerleyen çalışmalarda, farklılıkların yönetimi uygulamalarının, örgütsel bağlllık, örgütsel vatandaşlık ve işten ayrılma niyeti gibi konulara etkilerinin iş tatmini aracılığında incelenmesi önerilmektedir. Uygulama açısından, yapılan bu çalışma ile birlikte literatürde yapılan diğer çalışmalar değerlendirilerek çalışanlara yönelik farklılıkların yönetimi uygulamalarında ar-ge çalışmaları yapılabilir. 


\section{EXTENDED ABSTRACT}

\section{Research on Determining the Impact of Employees' Perception of Diversity Management on Job Satisfaction

\author{
* \\ Mehmet Emre Güler-Tuğba Saraç-Osman Almadağ \\ İzmir Kâtip Çelebi University - Caresse a Luxury Collection Resort - The Ritz-Carlton Hotel
}

The meaning of workforce diversity has changed over the years. In this context, the scope of the concept, which was previously limited to gender or ethnicity, has been expanded by the variables of age, education, sexual orientation, physical ability, social status, economic status, lifestyle, religion. In summary, diversity is a multidimensional concept, and its management is critical. This study covers the employees at two hotels of an international hotel chain in different geographies. In this context, it will be tried to contribute to the literature by investigating the effect of management of differences on job satisfaction in hotel businesses with high employee turnover. In the studies conducted, it has been observed that studies examining the effect of employees' perceptions of differences in management practices on job satisfaction are not emphasized in the literature specifically for accommodation establishments.

Managing diversity includes various activities related to raising awareness and attracting the attention of managers. These activities are; Cooperation within the working life of members of different groups supports values and assumptions that may affect the way they compete, communicate, plan, organize, and motivate (Langer, 1989). Thus, by the purpose of evaluating differences, synergies can be created by using the strengths of each individual or subgroup (Tung, 1995). Thanks to effective difference management, different teams aim to achieve more innovation and creativity and thus provide superiority over homogeneous teams (Cox and Blake, 1991; Richard, 2000; Eroğlu and Çalışır, 2019). In other words, different teams dealing with problem-solving in a broader range can encourage speed and innovation and produce significantly higher quality solutions. 
Ignoring the problems that arise due to difference leads to conflicts that negatively affect their potential among employees (Christensen-Hughes, 1992; Sürgevil, 2008); well-managed differences can present opportunities and benefits by offering different perspectives and experiences that ensure the continuity and flexibility of the business (Day, 2007; Budak et al., 2009).

On the other hand, Job satisfaction emerges as a driving force for employees to satisfy their motivations and needs, as well as their emotional responses to the real conditions of the job. In other words, job satisfaction is affected by the harmony of the employee and employer's mutual expectations; Satisfaction or dissatisfaction occurs by evaluating personal and organizational factors together. Some of these factors are; work-life quality, working conditions, working environment, studies on differences that can be listed as meeting the psychological, economic, and social needs of the employees (Parvin and Kabir, 2011). Job satisfaction or dissatisfaction also; It is also affected by demographic factors such as age, gender, and education level (Sinha and Shukla, 2013). In the study of Pitts (2009), non-white workers are less likely to experience higher levels of job satisfaction than white workers, and men are less likely to show higher job satisfaction than women, and those with higher management authority are more likely to report higher job satisfaction. It is. On the other hand, Ordu (2016) stated that there is a significant positive relationship between management of differences and job satisfaction, and between the management of differences and individual performance.

In this research, it is aimed to reveal how the employees perceive the practices related to the management of differences in an internationally operating hotel chain and to determine the effect of this perception on job satisfaction.

The data was obtained online to the employees of all the departments of the hotel chain of the research subject in Istanbul and Jeddah, within one month. It is reported that there are approximately 450 employees in full and part-time in two hotels. Necessary preliminary information about the purpose of the study was given to 149 participants who were included in the study with the secure sampling method.

For the study, it was determined that the effects of management practices, which are positively perceived by the participants, on job satisfaction, are also positive. In this context, it can be perceived that with such practices 
carried out by businesses, employees are seen as individuals and evaluated according to their competencies, not their differences, and this can affect increasing job satisfaction. In this context, Madera et al. (2013) and Madera et al. As in (2016) 's studies, the result of management of differences has a positive effect on job satisfaction, and is supported by the research conducted in chain hotels with the help of hotel businesses.

In the following studies, it is recommended to examine the effects of management of differences on issues such as organizational commitment, organizational citizenship, and intention to quit, through job satisfaction. In terms of implementation, together with this study, other studies in the literature can be evaluated, and R\&D studies can be conducted in management practices of differences for employees.

\section{Kaynakça / References}

Akyol Mayatürk, E. (2016). A discussion about personal characteristics of entrepreneurs in the context of culture's impact. Business $\mathcal{E}$ Management Studies: An International Journal, 4(1), 63-83.

Barrows, C. W., ve Powers, T. (2008). Introduction to management in the hospitality industry, study guide. John Wiley \& Sons.

Bartz, D. E., Hillman, L. W., Lehrer, S., ve Mayhugh, G. M. (1990). A model for managing workforce diversity. Management Education and Development, 21(4), 321-326.

Brodbeck, F. C., Frese, M., Akerblom, S., Audia, G., Bakacsi, G., Bendova, H., ve Castel, P. (2000). Cultural variation of leadership prototypes across 22 European countries. Journal of occupational and organizational psychology, 73(1), 1-29.

Budak, G., Mayatürk, E., ve Sürgevil, O. (2009). Expatların etkili çalışmasında insan kaynakları yönetiminin rolü. Anadolu Bil Meslek Yüksekokulu Dergisi, 13, 51-64.

Christensen-Hughes, J. (1992). Cultural diversity: The lesson of Toronto's hotels. The Cornell hotel and restaurant administration quarterly, 33(2), 78-87.

Cox, T. H., ve Blake, S. (1991). Managing cultural diversity: Implications for organizational competitiveness. The Executive, 5(3), 45-56.

Davis, S. K. (2008). The relationships among nurse managers' perceptions of workplace diversity, cultural competence and job satisfaction. Ph.D. Dissertations University of California-San Francisco. 
Day, R. (2007). Developing the multi-cultural organization: managing diversity or understanding differences?. Industrial and Commercial training, 39(4), 214-217.

Eroğlu, S. E., ve Çalışır, V. (2019). Diversity management in turkish enterprises. OPUS-Uluslararası Toplum Araştırmaları Dergisi, 10 (17), 23242336. DOI: $10.26466 /$ opus. 530350

Gardenswartz, L., ve Rowe, A. (1998). Why diversity matters. HR focus, 75(7), S1-S1.

Gordon, J. (1995). Different from what? Diversity as a performance issue. Training, 32(5), 25-32.

Gröschl, S. (2011). Diversity management strategies of global hotel groups: a corporate web site based exploration. International Journal of Contemporary Hospitality Management, 23(2), 224-240.

Gröschl, S., ve Doherty, L. (1999). Diversity management in practice. International Journal of Contemporary Hospitality Management, 11(6), 262-268.

Horwitz, F. M., Bowmaker-Falconer, A., ve Searll, P. (1996). Human resource development and managing diversity in South Africa. International Journal of Manpower, 17(4/5), 134-151.

Iles, P. (1995). Learning to work with difference. Personnel Review, 24(6), 44-60.

Kandola, B. (1995). Selecting for diversity. International Journal of Selection and Assessment, 3(3), 162-167.

Kossek, E. E., Lobel, S. A., ve Brown, J. (2006). Human resource strategies to manage workforce diversity. Handbook of workplace diversity, 53-74.

Kunze, F., Boehm, S. A., ve Bruch, H. (2011). Age diversity, age discrimination climate and performance consequences - a cross organizational study. Journal of organizational behavior, 32(2), 264-290.

Langer, E. J. (1989). Mindfulness. Addison-Wesley/Addison Wesley Longman.

Lawler, J. (1996). Managing diversity at work. Human Resources at Work, ed. C. Molander, Lund: Studentlitteratur, 159-185.

Locke, E. (1976). The nature and causes of job satisfaction. Handbook of Industrial and Organizational Psychology (p.p. 1297-1349). Editor M. D. Dunnette. Chicago: Rand McNally.

Madera, J. M., Dawson, M., ve Neal, J. A. (2013). Hotel managers' perceived diversity climate and job satisfaction: The mediating effects of role ambiguity and conflict. International Journal of Hospitality Management, 35, 28-34. 
Madera, J. M., Dawson, M., ve Guchait, P. (2016). Psychological diversity climate: justice, racioethnic minority status and job satisfaction. International Journal of Contemporary Hospitality Management, 28(11), 2514-2532.

Manoharan, A., Gross, M. J., ve Sardeshmukh, S. R. (2014). Identityconscious vs identity-blind: Hotel managers' use of formal and informal diversity management practices. International Journal of Hospitality Management, 41, 1-9.

McKay, P. F., Avery, D. R., ve Morris, M. A. (2008). Mean racial-ethnic differences in employee sales performance: The moderating role of diversity climate. Personnel Psychology, 61(2), 349-374.

McLaughlin, M. E., Bell, M. P., ve Stringer, D. Y. (2004). Stigma and acceptance of persons with disabilities: Understudied aspects of workforce diversity. Group \& Organization Management, 29(3), 302-333.

McNerney, D. (1994). The bottom-line value of diversity. HR Focus, 71(5), 22-23.

Nişancl, Z. N., Akyol Mayatürk, E., ve Özmutaf, N. M. (2016). Farklılıklar kapsamında davranış tarzları ve bireysel performans: beyaz ve mavi yakalı çalışan perspektifi. Yönetim ve Ekonomi: Celal Bayar Üniversitesi İktisadi ve İdari Bilimler Fakültesi Dergisi, 23(1), 287-307.

Nykiel, R. A. (1997). Enhancing quality through diversity. Journal of Hospitality \& Leisure Marketing, 4(4), 65-70.

Olsen, J. E., ve Martins, L. L. (2012). Understanding organizational diversity management programs: A theoretical framework and directions for future research. Journal of Organizational behavior, 33(8), 1168-1187.

Ordu, A. (2016). The effects of diversity management on job satisfaction and individual performance of teachers. Educational Research and Reviews, 11(3), 105-112.

Parvin, M. M. ve Kabir, M. N. (2011). Factors affecting employee job satisfaction of pharmaceutical sector. Australian Journal of Business and Management Research. 1(9), 113-123

Pearsall, M. J., Ellis, A. P., ve Evans, J. M. (2008). Unlocking the effects of gender faultlines on team creativity: Is activation the key? Journal of Applied Psychology, 93(1), 225.

Peccei, R., ve Lee, H. J. (2005). The impact of gender similarity on employee satisfaction at work: A review and re-evaluation. Journal of Management Studies, 42(8), 1571-1592. 
Pitts, D. (2009). Diversity management, job satisfaction, and performance: Evidence from US federal agencies. Public Administration Review, 69(2), 328-338.

Richard, O. C. (2000). Racial diversity, business strategy, and firm performance: A resource-based view. Academy of management journal, 43(2), 164-177.

Ross, R., ve Schneider, R. (1992). From equality to diversity: A business case for equal opportunities.

Sinha, D. ve Shukla, S. K. (2013). Study of Job Satisfaction of the Employees of Private Sector Banks. International Journal of Education and Psychological Research. 2(2), 33-40.

Sürgevil, O. (2008). Farklılık kavramına ve farklılıkların yönetimine temel oluşturan sosyo-psikolojik kuramlar ve yaklaşımlar. Balıkesir Üniversitesi Sosyal Bilimler Enstitüsü Dergisi, 11(20), 111-124.

Sürgevil, O. ve Budak, G. (2008). İşletmelerin farklılıkların yönetimi anlayışına yaklaşım tarzlarının saptanmasına yönelik bir araştırma. Dokuz Eylül Üniversitesi Sosyal Bilimler Enstitüsü Dergisi, 10(4), 65-96.

Tung, R.L. 1995. The global human resource challenge: managing diversity in international settings: Proceedings of the 10th World Congress of the International Industrial Relations Association. Washington DC. 31 May4 June, 1995. 16-24.

TDK. (2011). Büyük Türkçe sözlük. Ankara: Türk Dil Kurumu.

Van Knippenberg, D., ve Schippers, M. C. (2007). Work group diversity. Annu. Rev. Psychol., 58, 515-541.

Witt, A. L., Nye, L. G. (1992). Gender and the relationship between perceived fairness of pay or promotion and job satisfaction. Journal of Applied Psychology. 77(6), 910-917.

Wrench, J. (2008). Diversity management and discrimination: Immigrants and ethnic minorities in the EU. Human Resource Management International Digest, 16(4).

\section{Kaynakça Bilgisi / Citation Information}

Güler, M. E., Saraç, T., ve Almadă̆, O. (2020). Çalışanların farklılıkların yönetimi ile ilgili algılarının iş tatminine etkisini belirlemeye yönelik bir araştırma. OPUS-Uluslararası Toplum Araştırmaları Dergisi, 15(24), 2394-2412. DOI: 10.26466/opus.639658 